\title{
Multiple atmospheric layering and mixing-layer height in the Inn valley observed by remote sensing
}

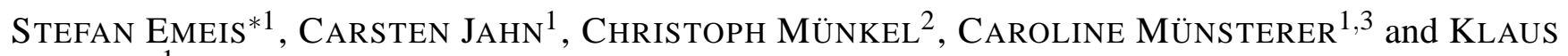 \\ SCHÄFER ${ }^{1}$ \\ ${ }^{1}$ Forschungszentrum Karlsruhe GmbH, Institut für Meteorologie and Klimaforschung, Garmisch-Partenkirchen, \\ Germany \\ ${ }^{2}$ Vaisala GmbH, Hamburg, Germany \\ ${ }^{3}$ Universität Heidelberg, Fakultät für Physik und Astronomie, Heidelberg, Germany
}

(Manuscript received October 30, 2006; in revised form April 4, 2007; accepted April 4, 2007)

\begin{abstract}
Automatic mixing layer height monitoring was performed by continuous sodar and ceilometer measurements in the Inn valley east of Innsbruck, Austria during a winter measuring campaign on air and noise pollution. The ceilometer, an eye-safe commercial lidar originally designed to detect cloud base heights and vertical visibility for aviation safety purposes, was operated for about two months; the sodar was operated for more than four months. Special software for this ceilometer provides routine retrievals of multiple aerosol layers and mixing layer height from the optical backscatter data. An existing retrieval method for the mixing layer height from sodar data has also been enhanced in order to detect multiple atmospheric layering. Particular emphasis is given to the detection of thermally stable layers and inversions within the lower valley atmosphere and their temporal development. Such layers influence significantly the diurnal variations of air pollution and traffic noise impact. A comparison is performed with parallel mixing layer height retrievals from the sodar and the ceilometer. In clear and cold winter nights sometimes several layers one above the other can be detected with both instruments. These multiple layers form due to an interaction between the mountain wind and the down-slope winds. In the absence of low clouds and precipitation ceilometers can estimate the mixing-layerheight fairly well. Ceilometer and sodar partly complement each other.
\end{abstract}

\section{Zusammenfassung}

Eine automatische Überwachung der Mischungsschichthöhe im Inntal östlich Innsbrucks ist mit kontinuierlichen Messungen mit einem Sodar und einem Ceilometer durchgeführt worden. Die Messungen gehörten zu einer Wintermesskampagne, die die Bedingungen für Lärm- und Schadstoffausbreitungen erfassen sollte. Das Ceilometer, ein augensicheres Gerät, welches ursprünglich zur Bestimmung der Höhe der Wolkenuntergrenze und der vertikalen Sichtweite entwickelt worden war, wurde für zwei Monate betrieben, das Sodar wurde für mehr als vier Monate betrieben. Eine spezielle Software ermöglicht die Analyse mehrfach übereinander liegender Aerosolschichten und der Mischungsschichthöhe aus den optischen Rückstreuintensitäten. Eine existierende Analysemethode für die Mischungsschichthöhe für das Sodar ist ebenfalls erweitert worden, um mehrfache Schichtbildung zu erfassen. Besonderes Gewicht wird hier auf die Erkennung thermisch stabiler Schichten und Inversionen in der unteren Talatmosphäre und deren zeitliche Entwicklung gelegt. Solche Grenzschichtstrukturen haben einen deutlichen Einfluss auf die täglichen Variationen der Luft- und Lärmbelastung. Die Algorithmen für die beiden Fernmessverfahren werden für einen Zeitraum, für den parallele Messungen vorliegen, verglichen. Dabei zeigt sich, dass es in klaren und kalten Winternächten häufiger zur Ausbildung von mehreren, übereinander liegenden Schichten kommt, die von beiden Geräten erfasst werden. Diese Mehrfachschichtung ist auf ein Wechselspiel zwischen dem Bergwind und den Hangabwinden zurückzuführen. Solange keine Wolken oder etwaiger Niederschlag stören, kann das Ceilometer die Mischungsschichthöhe gut erfassen. Ceilometer und Sodar stellen teilweise eine gute Ergänzung zueinander dar.

\section{Introduction}

The thermal layering of the atmospheric boundary layer and the existence of inversions in this layer or on the top of it have a strong influence on the development

\footnotetext{
* Corresponding author: Stefan Emeis, Forschungszentrum Karlsruhe $\mathrm{GmbH}$, Institut für Meteorologie und Klimaforschung, Atmosphärische Umweltforschung (IMK-IFU), Kreuzeckbahnstr. 19, 82467 Garmisch-Partenkirchen, Germany, e-mail: stefan.emeis@imk.fzk.de
}

of episodes of high concentrations of air pollutants and noise annoyance near the Earth's surface which might be harmful to people and ecosystems. The height of the mixing layer (MLH) is defined as the height up to which vertical dispersion by turbulent mixing of air pollutants takes place. Both, thermal layering and MLH also influence the noise propagation. Low elevated inversions can lead to noise ducts which can convey traffic noise over large horizontal distances. Due to the limiting role of the stable stratification above and the inversion at the top of 
the mixing layer most of the aerosol particles in an atmospheric column are usually confined to atmospheric layers below MLH, the knowledge on MLH can thus be employed to convert column-mean optical depths measured from satellites into near-surface air quality information (SIFAKIS et al., 1998). MLH depends heavily on the synoptic weather situation. Over level terrain in Central Europe, MLH can easily reach $2000 \mathrm{~m}$ and more above ground level in spring and summer.

The use of modern ground-based remote sensing techniques to follow the diurnal variations of the atmospheric layering and MLH seems promising (EMEIS et al., 2004). Sound waves are scattered at temperature gradients (either mean or turbulent ones) in the atmosphere, light waves at small particles (Mie scattering) or at air molecules (Rayleigh scattering). Particles may serve as good indicator of atmospheric layering because - as mentioned above - their vertical distribution is heavily influenced by the thermal structure of the atmosphere (NEFF and COULTER, 1986). BEYRICH (1997) has listed possible analyses which can be made from acoustic backscatter intensities measured by a sodar. A more sophisticated method which makes use of the acoustic backscatter intensity and the variance of the vertical velocity component simultaneously is described in EMEIS and TÜRK (2004). A general overview on MLH determination possibilities is given in SEIBERT et al. (2000). Direct detection of MLH from acoustic backscatter intensities is limited to the order of about 1 $\mathrm{km}$ due to the rather high attenuation of sound waves in the atmosphere. In contrast, optical remote sensing offers much larger height ranges of at least several kilometres, because the attenuation of light waves in the atmosphere is small unless there is fog, clouds or heavy precipitation. An estimation of MLH from optical backscatter intensities measured by a ceilometer is presented in SCHÄFER et al. (2004, 2005). A first comparison of parallel measurements of the vertical structure of the atmospheric boundary layer by a ceilometer and a sodar is described in EMEIS and SCHÄFER (2006).

In valleys in mountainous areas, due to local thermal circulations within these valleys (upslope winds and corresponding sinking motion above the centreline of the valley), MLH is often much lower than over level terrain. Usually the inversion on the top of the mixing layer persists during the whole day at heights slightly below the crest height of the surrounding mountains (VERGEINER and DREISEITL, 1987). The special features of mixing layers in valleys on the other hand enhance the possibility that the structure and the top of the mixing layer can be detected by ground-based remote sensing systems. Extremely pronounced formation of shallow stable layers and elevated inversions can take place in deep, snow-covered valleys in winter with clear skies. Mountain and valley winds scarcely form in snow-covered mountains because the heating of elevated surfaces is negligible due to the high albedo of the snow cover. The therefore low mean wind speed along the valley axis and the strong radiative cooling of the ground prevent nearly any vertical mixing and thus the interplay of the weak valley and slope winds can lead to complex vertical structures of the valley atmosphere. This includes the formation of multiple elevated inversions within a few hundred metres above ground that can persist for many hours. The method by EMEIS and TÜRK (2004) has to be extended further in order to detect this multiple layering from sodar data. This extension and its application to a data set from an Alpine valley are described in this paper. The results will be compared and complemented by results from a likewise enhanced analysis scheme based on the one described by SCHÄFER et al. (2004) for ceilometer data. The data set is from a field study performed in the Inn valley within the frame of the project ALPNAP which is an ongoing European Union research project focussing on major transit routes cutting through the European Alps.

\section{Methodology}

In the following subsections we will describe the algorithms with which the MLH is derived from groundbased acoustic and optical remote sensing data. The derivation will be based on the backscatter intensity and - in case of the sodar - on the variance of the vertical velocity component. This is a specialized usage of remote sensing devices that today are frequently used for wind and turbulence measurements (ENGELBART et al., 2007; EMEIS et al., 2007). In the following we will denote with the letter $\mathrm{H}$ and an attached number certain derived heights which are related to inversions and the MLH; while we will use the variable $\mathrm{z}$ to denote the normal vertical coordinate.

\subsection{Acoustic detection of MLH}

From the acoustic remote sensing data the following features will be analysed by an automated procedure:

- the height of a turbulent layer (H1) characterised by high acoustic backscatter intensities $\mathrm{R}(\mathrm{z})$ due to thermal fluctuations (therefore having a high variance of the vertical velocity component $\sigma_{w}$ ),

- up to five lifted inversions (H2_1 to H2_5) characterized by secondary maxima of acoustic backscatter due to a sharp increase of temperature with height and simultaneously low $\sigma_{w}$, and

- the height of a surface-based stable layer (H3) characterised by high backscatter intensities due to a large mean vertical temperature gradient starting directly at the ground and having a low variance of the vertical velocity component. 
The mixing layer height (MLH) is defined as the minimum of the heights H1, the lowest H2 (H2_1), and H3. Details for the determination of $\mathrm{H} 1$ and just one lifted inversion $\mathrm{H} 2$ are described in EMEIS and TÜRK (2004). The determination of up to five lifted inversions is made for the first time in the present study. Acoustic remote sensing by a SODAR also yields wind fields that in principle could be used for determination of the mixing layer height, too. Because the wind information above the inversion was not regularly available, wind data have not been included into the scheme for the determination of the mixing layer height.

The height $\mathrm{H} 1$ corresponds to a sharp decrease of the acoustic backscatter intensity $\mathrm{R}(\mathrm{z})$ with height $\mathrm{z}$ usually indicating the top of a turbulent layer:

$$
\begin{aligned}
& \mathrm{H} 1=z, \text { if }(R(z)<88 \mathrm{~dB} \\
& \text { and } R(z+1)<86 \mathrm{~dB} \text { and } R(z+2)<84 \mathrm{~dB}) .
\end{aligned}
$$

The $\mathrm{dB}$ values are derived from an arbitrary scale because the received backscatter intensities cannot be calibrated. The $R(z)$ values are specific for the SODAR used in this study, and they are given for illustration purposes only.

Elevated inversions are diagnosed from secondary maxima of the backscatter intensity that are not related to high turbulence intensities. For elevated inversions we stipulate an increase in backscatter intensity below a certain height $\mathrm{z}=\mathrm{H} 2$ and a decrease above while the turbulence intensity is low:

$$
\begin{aligned}
& \mathrm{H} 2 \_n=z, \text { if }\left(\partial R /\left.\partial z\right|_{z+1}<0 \text { and } \partial R /\left.\partial z\right|_{z-1}>0\right. \\
& \text { and } \left.\sigma_{w}<0.70 \mathrm{~ms}^{-1}\right)
\end{aligned}
$$

for $\mathrm{n}=1, \ldots, 5$. The determination of the height of the stable surface layer $\mathrm{H} 3$ is started if the backscatter intensity in the lowest range gates is above $105 \mathrm{~dB}$ while $\sigma_{w}$ is smaller than $0.3 \mathrm{~ms}^{-1}$. The top of the stable layer $\mathrm{H} 3$ is at the height where either the backscatter intensity sinks below $105 \mathrm{~dB}$ or $\sigma_{w}$ increases above $0.3 \mathrm{~ms}^{-1}$.

$$
\begin{aligned}
& \mathrm{H} 3=z, \text { if }(R(z)>105 \mathrm{~dB} \\
& \text { and } \left.R(z+1)<105 \mathrm{~dB} \text { and } \sigma_{w}(z)<0.3 \mathrm{~ms}^{-1}\right)
\end{aligned}
$$

or

$$
\begin{aligned}
& \operatorname{if}\left(\sigma_{w}(z)<0.3 \mathrm{~ms}^{-1}\right. \\
& \text { and } \left.\sigma_{w}(z+1)>0.3 \mathrm{~ms}^{-1} \text { and } R(z)>105 \mathrm{~dB}\right)
\end{aligned}
$$

If a surface-based stable layer with height $\mathrm{H} 3$ has been detected, the search for the first height H2_1 is started at the first range gate above $\mathrm{H} 3$, otherwise it starts at the lowest range gate. The search for elevated inversion is stopped when 5 elevated inversions have been found or the highest range gate of the available data has been reached.

The $\sigma_{w}$ values used in (2.2) and (2.3) have been determined by optimizing the automatic application of the detection algorithm. In doing so it turned out that no lifted inversions occurred with a variance $\sigma_{w}$ lower than $0.7 \mathrm{~ms}^{-1}$ and that the variance $\sigma_{w}$ in nocturnal stable surface layers was below $0.3 \mathrm{~ms}^{-1}$. The first $\sigma_{w}$ threshold made it possible to distinguish between inversions and elevated layers of enhanced turbulence. The latter $\sigma_{w}$ threshold made it possible to differentiate between nocturnal stable surface layers and daytime superadiabatic surface layers although both types of surface layers yield more or less the same level of backscatter intensity. Finally MLH from the acoustic remote sensing is determined as the minimum of $\mathrm{H} 1, \mathrm{H} 2 \_1$, and $\mathrm{H} 3$ :

$$
\mathrm{MLH}_{a c}=\min \left(\mathrm{H} 1, \mathrm{H} 2 \_1, \mathrm{H} 3\right)
$$

\subsection{Optical detection of MLH}

The heights of the near surface aerosol layers (H4_1 to H4_5) are characterized by minima of the vertical gradient (the term 'gradient minimum' is used here to denote the most negative value of the gradient, see also Fig. 1) of the optical attenuated backscatter intensity (B(z)). SCHÄFER et al. (2004) have discussed the principle of the retrieval of the height $\mathrm{H} 4$ with the lowest vertical gradient. For the present study this approach has been refined and extended to enable the calculation of up to five lifted inversions.

Prior to the determination of gradient minima the overlap and range corrected attenuated backscatter profiles have to be averaged over time and height to suppress noise generated artefacts. Therefore the $\mathrm{H} 4$ values are determined in a two-step procedure. Between $140 \mathrm{~m}$ and $500 \mathrm{~m}$ height sliding averaging is done over $15 \mathrm{~min}$ and a height interval $\mathrm{h}$ of $80 \mathrm{~m}$. In the layer between 500 and $2000 \mathrm{~m} \mathrm{~h}$ for vertical averaging is extended to $160 \mathrm{~m}$. Two additional parameters have been introduced to further reduce the number of false hits. The minimum accepted attenuated backscatter intensity $\mathrm{B}_{\text {min }}$ right below a lifted inversion is set to $200 * 10^{-9}$ $\mathrm{m}^{-1} \mathrm{sr}^{-1}$ in the lower layer and $250 * 10^{-9} \mathrm{~m}^{-1} \mathrm{sr}^{-1}$ in the upper layer. Additionally the vertical gradient value $\partial B / \partial z_{\max }$ of a lifted inversion must be more negative than $-0.3 * 10^{-9} \mathrm{~m}^{-2} \mathrm{sr}^{-1}$ in the lower layer and more negative than $-0.6 * 10^{-9} \mathrm{~m}^{-2} \mathrm{sr}^{-1}$ in the upper layer.

If $\mathrm{B}(\mathrm{z})$ denotes the measured attenuated backscatter intensity in the height $\mathrm{z}$ above ground averaged over time and height and $\Delta \mathrm{h}$ is the height averaging interval, then the gradient $\partial B / \partial z$ in the height $\mathrm{z}$ is calculated as

$$
\partial B /\left.\partial z\right|_{z}=(B(z+\Delta h / 2)-B(z-\Delta h / 2)) / \Delta h
$$




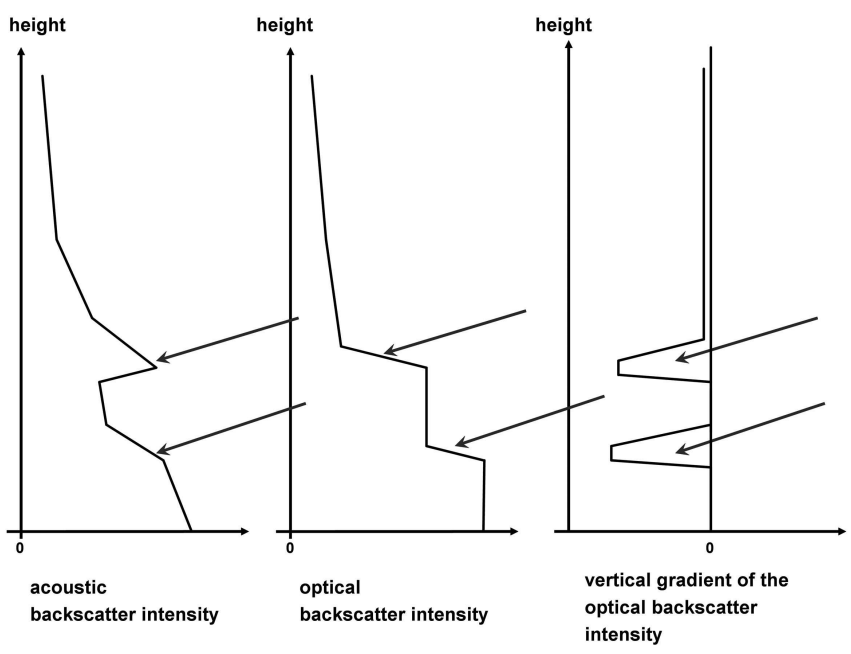

Figure 1: Schematic comparison of MLH determination algorithms in the case of a nocturnal stable surface layer and an elevated inversion above it. Left: vertical profile of acoustic backscatter intensity, middle: vertical profile of optical backscatter intensity, right: vertical profile of the vertical gradient of the optical backscatter intensity. Lower arrows mark the position of the height H3 (left) and H4_1 (middle and right). Upper arrows mark the heights H2_1 (left) and H4_2 (right).

A gradient minimum is characterized by a change of sign from minus to plus of the second derivative of $\mathrm{B}(\mathrm{z})$. The height interval under examination is searched from bottom to top for these gradient minima H4_n.

The second derivative of $\mathrm{B}(\mathrm{z})$ in the height $\mathrm{z}$ is

$$
\partial^{2} B /\left.\partial z^{2}\right|_{z}=\left(\partial B /\left.\partial z\right|_{z+\Delta h / 2}-\partial B /\left.\partial z\right|_{z-\Delta h / 2}\right) / \Delta h .
$$

There is a gradient minimum $\mathrm{H} 4$ _ $\mathrm{n}$ in the height $\mathrm{z}$ if the second derivative of $\mathrm{B}(\mathrm{z})$ one range gate below $\mathrm{z}$ is not positive, if the second derivative of $\mathrm{B}(\mathrm{z})$ in the height $\mathrm{z}$ is positive, and if the false hit conditions mentioned above are fulfilled:

$$
\begin{aligned}
& \mathrm{H} 4 \_n=z, \text { if }\left(\partial B /\left.\partial z^{2}\right|_{z-1} \leq 0 \text { and } \partial^{2} B /\left.\partial z^{2}\right|_{z}>0\right. \\
& \text { and } \left.B(z-\Delta h / 2) \geq B_{\text {min }} \text { and } \partial B /\left.\partial z\right|_{z} \leq \partial B / \partial z_{\max }\right)
\end{aligned}
$$

for $\mathrm{n}=1, \ldots, 5$.

The MLH from optical remote sensing is taken as the lowest height $\mathrm{H} 4$ :

$$
\mathrm{MLH}_{o p}=\mathrm{H} 4 \_1
$$

\subsection{Comparison of the two methods}

The comparison between the two schemes for the determination of MLH from acoustic and optical backscatter intensities reveals an interesting difference which should be noted carefully (see Fig. 1): While we need the acoustic backscatter intensity itself for the detection of $\mathrm{H} 1$ and $\mathrm{H} 3$ and the first derivative of this backscatter intensity for the determination of $\mathrm{H} 2$, we need the first and the second derivative of the optical backscatter intensity (but not the optical backscatter intensity itself) to determine H4. This difference in the processing of the backscatter intensities is due to the different scattering processes for acoustic and optical waves: Acoustic waves are scattered at atmospheric refractivity gradients and thus at temperature gradients (NEFF and COULTER, 1986) while optical waves are scattered at small particles. Therefore the optical backscatter intensity is proportional to the aerosol concentration itself. The MLH on the other hand, which we desire to derive from these backscatter intensities, is in both cases found in heights where we have vertical gradients of the temperature and of the aerosol concentration. Therefore, in principle, the vertical distribution of the acoustic backscatter intensity should look very much alike the vertical distribution of the vertical gradient of the optical backscatter intensity.

The analysis of the sodar data and the ceilometer data can be combined to one single MLH information by forming the minimum from (2.4) and (2.8):

$$
\mathrm{MLH}=\min \left(\mathrm{MLH}_{a c}, \mathrm{MLH}_{o p}\right)
$$

\section{Site and instrumentation}

\subsection{Measurement site}

The field campaign of ALPNAP, from which the data in this study are taken, was performed between October 2005 and February 2006 in the lower Inn valley in Austria. The target area was centered on Schwaz / Vomp $\left(47^{\circ} 20^{\prime} \mathrm{N} / 11^{\circ} 41^{\prime} \mathrm{E} / 540 \mathrm{~m}\right.$ a.s.l.), where exceedances of nitrogen dioxide and PM10 are frequently recorded from the existing routine air pollution measurement network. A SODAR and a ceilometer were operated close to each other from the flat valley floor southwest of Schwaz. The period when both instruments were operated simultaneously ended on January 18, 2006. The Inn valley is here a few kilometres wide and the valley axis is orientated from the Southwest towards the Northeast. The mountains at both sides of the valley are more than $1500 \mathrm{~m}$ higher than the valley floor.

\subsection{Sodar}

The sodar is a monostatic Doppler sodar DSDR3 7 of METEK (Fig. 2 left) with three separate antennas (REITEBUCH and EMEIS, 1998). Each antenna contains seven sound transducers. Two of the antennas are inclined $20^{\circ}$ from the vertical. The acoustic frequency is about $1500 \mathrm{~Hz}$. The instrument is optimised for longrange detection up to $1300 \mathrm{~m}$ above ground in ideal conditions without external noise sources. Here, a vertical 

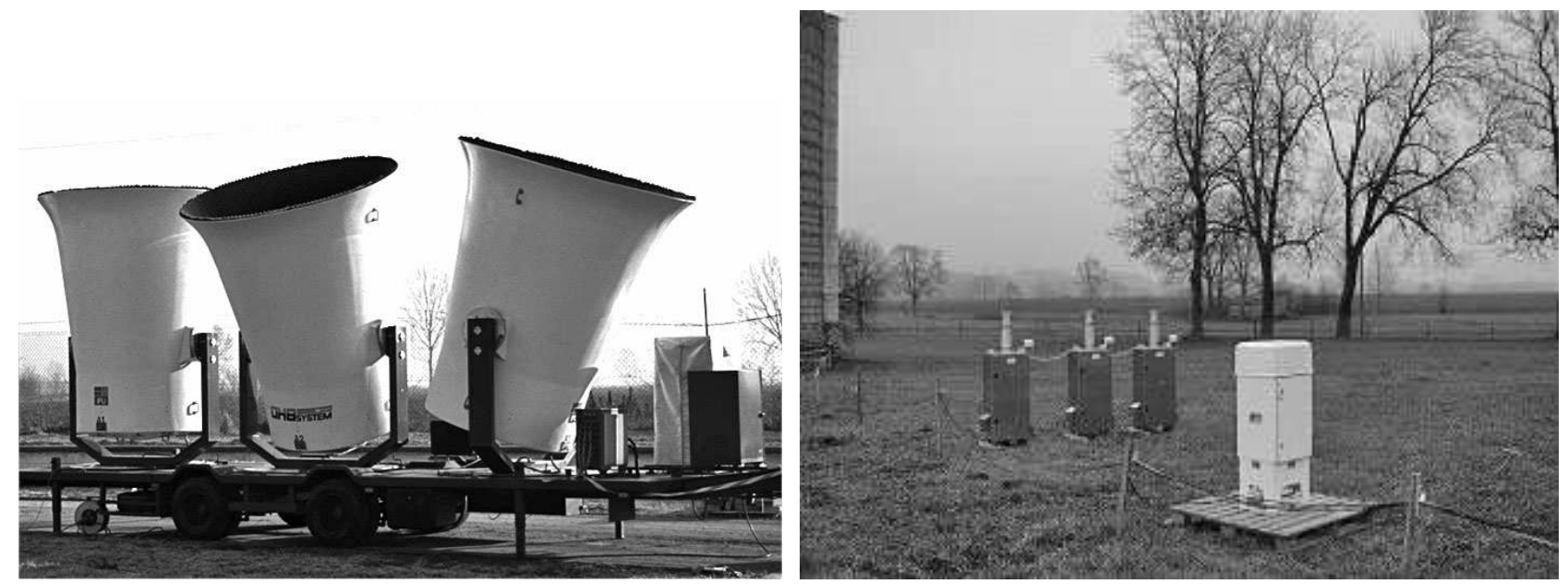

Figure 2: DSDR3x7 sodar (left) and LD 40 ceilometer (right).

range of $1000 \mathrm{~m}$ for the backscatter intensity, a vertical resolution of $20 \mathrm{~m}$, and a temporal averaging over 15 min have been used. The acoustic backscatter intensity is mainly determined by turbulent temperature fluctuations and strong mean vertical temperature gradients such as inversions. The determination of all three mean wind components and the variance of the vertical velocity component $\sigma_{w}$ from the Doppler shift in the return signal require a certain signal-to-noise ratio and thus the vertical range for these variables from sodar measurements depends strongly on the meteorological conditions. This range is considerably lower than the one for the backscatter intensity and typically varies between a few hundred meters and about $800 \mathrm{~m}$.

\subsection{Ceilometer}

The ceilometer is a double-lens ceilometer LD 40 (Fig. 2 right) from Vaisala (MÜNKEL et al., 2004). It measures the optical attenuated backscatter intensity at $0.855 \mu \mathrm{m}$ averaged over $15 \mathrm{~s}$. This special wavelength has been chosen because the absorption by water vapour is much lower here than at $0.910 \mu \mathrm{m}$; a wavelength for which laser diodes are easily available. $0.885 \mu \mathrm{m}$ would have been ideal but no laser diodes were available for this wavelength. The typical vertical range of this instrument is $4000 \mathrm{~m}$; the vertical resolution used here is $7.5 \mathrm{~m}$. Apart from the very strong backscatter from clouds (that is what the instrument had originally been designed for) and fog, weaker gradients in the backscatter intensity are mainly determined by the number and the size spectrum of aerosol particles floating in the air. Reliable analysis of the vertical profile of particle-induced backscatter can be made from heights above about $140 \mathrm{~m}$. Below that height the overlap between the emitted beam and the field-of-view of the receiver is smaller than $30 \%$. The overlap is 0 for heights below $60 \mathrm{~m}$. Any signal received from distances below $60 \mathrm{~m}$ is generated by multiple scattering and scattering of light at dust and dirt particles on the weather protection glass of the transmitter into the field-of-view of the receiver. A slight contamination of the glass thus results in a signal amplitude decrease for distances above $60 \mathrm{~m}$, but a signal amplitude increase for distances below $60 \mathrm{~m}$.

\section{Results}

Fig. 3 shows backscatter data from the ceilometer and the sodar for four days in January 2006 which were characterized by a very strong stable stratification of the valley air mass. The ground was covered with snow and it had clear skies all these days. In the left-hand frames of Fig. 3 the optical backscatter intensity from the ceilometer recordings is displayed together with an analysis of local minima from the vertical gradient of this backscatter intensity in the height interval between 140 and $500 \mathrm{~m}$ (see section 2.2). The latter is an indicator for the top of a surface-based stable layer or a lifted inversion.

We see persisting surface-based stable layers and especially in the early morning hours and the late evening hours several lifted inversions detectable from the aerosol distribution. Both features compare well with the information from the SODAR acoustic backscatter intensity which is given by different colours showing the layering of the atmosphere by enhanced intensities (right-hand frames of Fig. 3).

We see characteristic patterns which appear during each of these days. There seems to be high aerosol content or even fog in the layer below $100 \mathrm{~m}$ in the first half of the day and increased aerosol content below 400 to $600 \mathrm{~m}$ during this time. Optical backscatter intensities are generally lower in the early afternoon but increase again in the later afternoon. The acoustic backscatter shows a similar behaviour. There are high backscatter intensities in the first half of the day below 200 to 300 $\mathrm{m}$ (probably due to stable thermal layering because $\sigma_{w}$ 

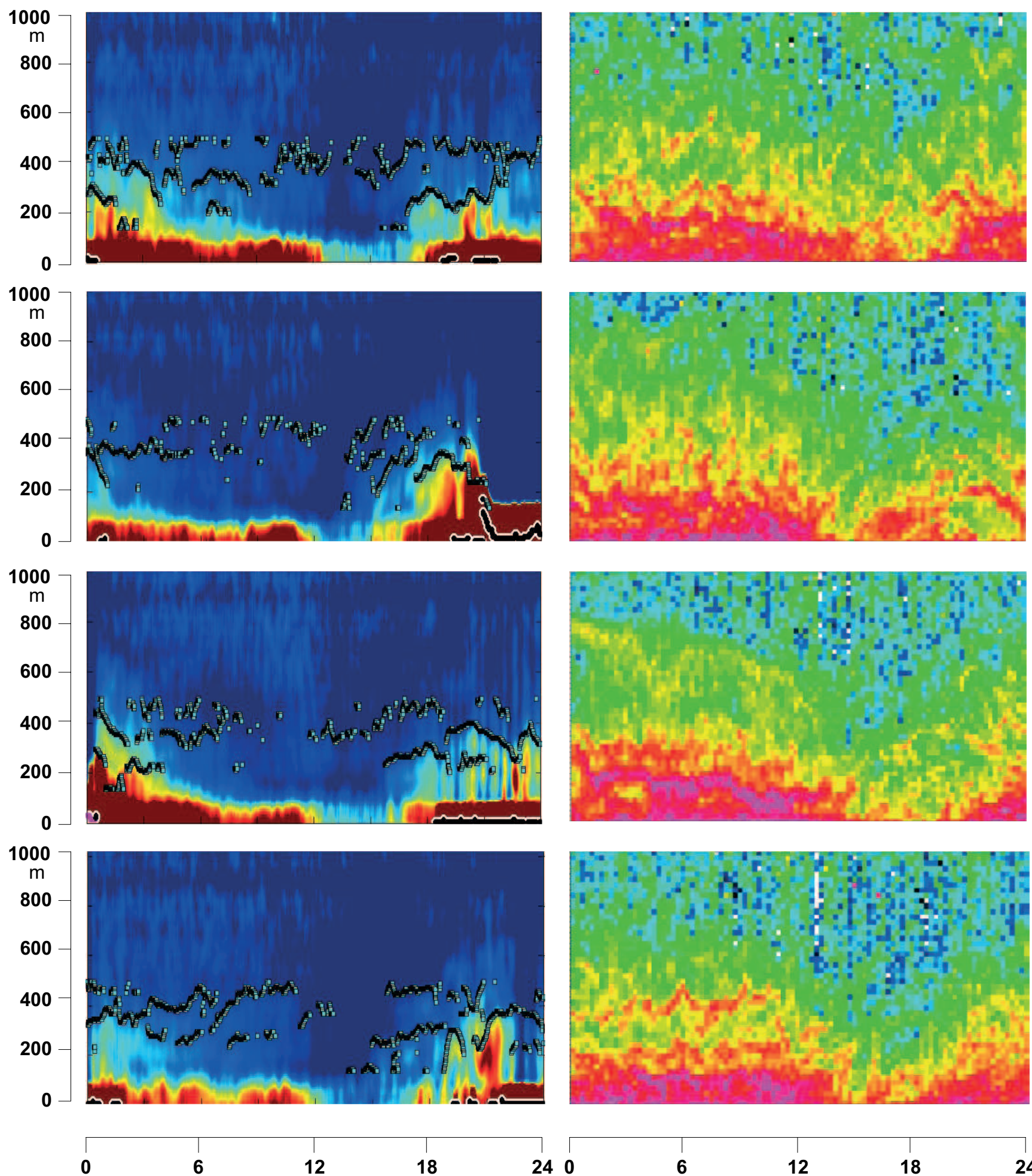

12

18

240

6

12

18

24

Figure 3: Optical backscatter intensity (brown: high backscatter, dark blue: low backscatter) measured by the ceilometer and acoustic backscatter intensity (purple: high backscatter, blue: low backscatter) measured by the SODAR on 06, 07, 08, and 09 January 2006 during 24 hours each from above to the bottom. Local minima of the vertical gradient of the ceilometer backscatter intensity are marked by dots with black shadow in the left-hand frames indicating a surface-based stable layer or lifted inversions. The acoustic backscatter intensity is given in the right-hand frames by different colours showing by enhanced intensities the layering of the atmosphere.

is simultaneously very low) and increased intensities up to 500 to $700 \mathrm{~m}$ during this time. The backscatter is reduced during the afternoon hours but re-appears in the evening when a new stable surface layer forms. Secondary lifted inversions can already be detected from this Figure, especially from the acoustic backscatter de- 

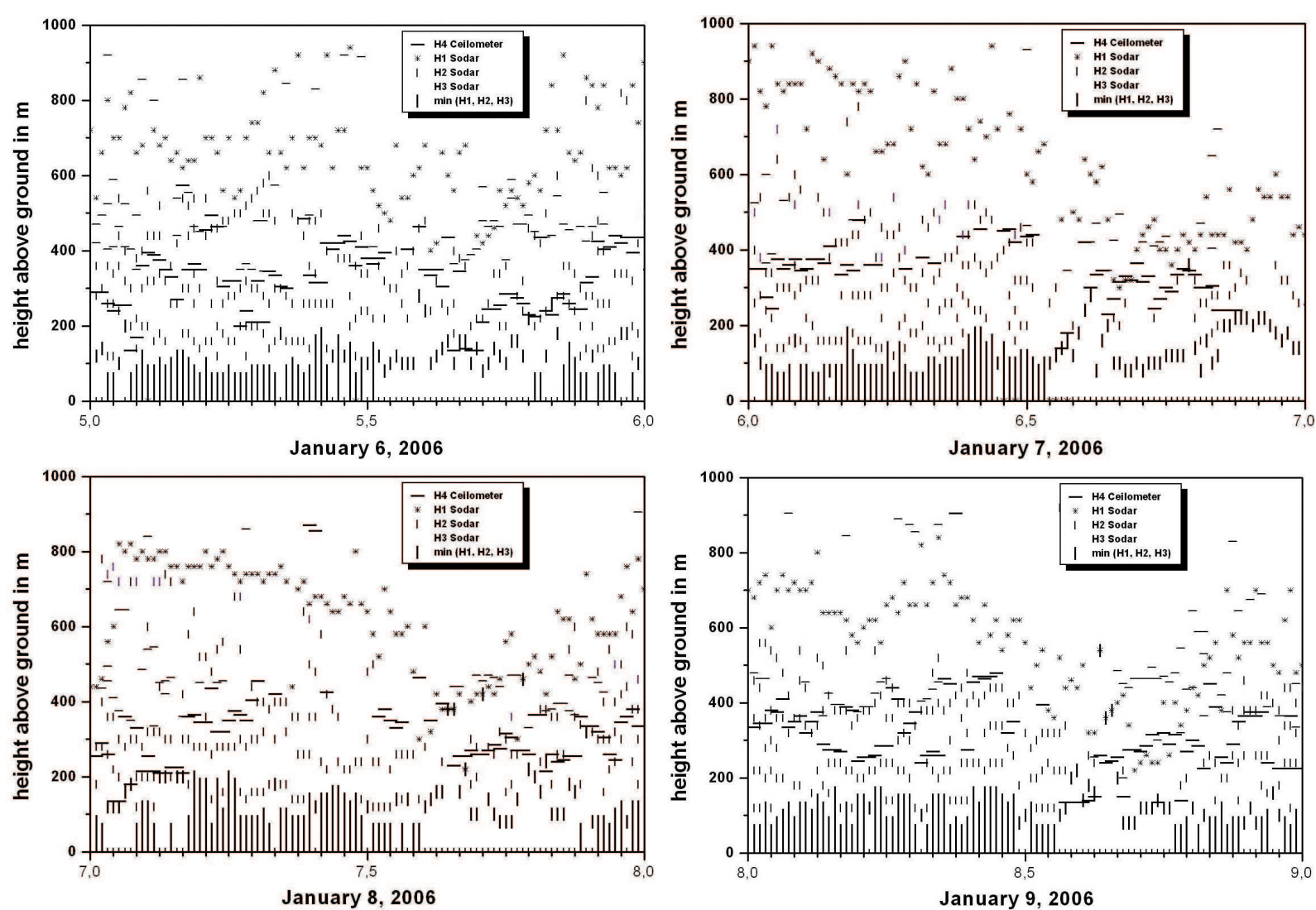

Figure 4: H1 (dots), up to five acoustically-detected lifted inversions H2 (short vertical bars), acoustically-detected surface-based inversions H3 (vertical lines starting from the ground), and optically-detected lifted inversions H4 (horizontal bars) for four days (January 6-9, 2006). The lowest height $\mathrm{H} 4$ and the minimum of $\mathrm{H} 1, \mathrm{H} 3$, and the lowest height $\mathrm{H} 2$ are plotted in bold.
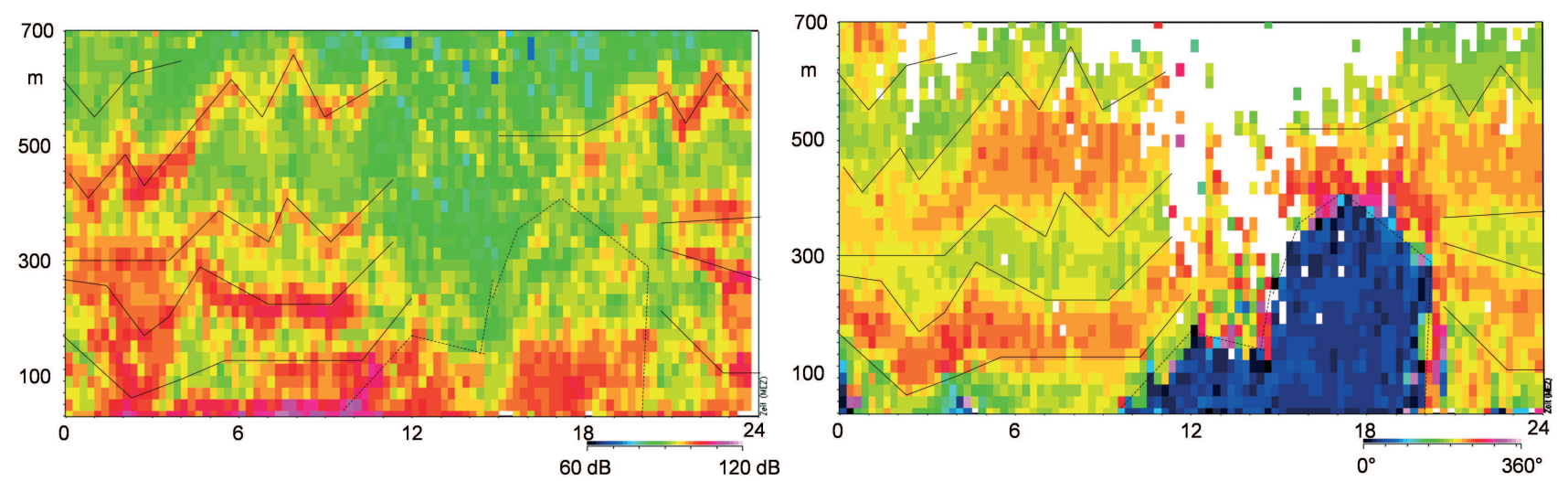

Figure 5: Acoustic backscatter intensity (left; purple and red: high, green: low) and wind direction (right; green: down-slope winds, red: down-valley winds, and blue: up-valley winds) from the sodar measurements on January 29, 2006. The lines in the two Figures have been analysed from the wind direction changes in the right-hand frame.

picted in the lower right frame. Please note when looking for secondary lifted inversions that - according to what has been stated in section 2.3 - secondary maxima in the acoustic backscatter intensity correspond to vertical gradients in the optical backscatter intensity. This can most clearly be seen in the lowest two frames for January 9, 2006.

Fig. 4 shows a comparison of the MLH derived from the backscatter intensities shown in Fig. 3 and the $\sigma_{w}$ information from the sodar using the methods described in section 2.1 and 2.2. During the first half of the day the sodar data indicate a continuously increasing temperature in the layer between the ground and about $100 \mathrm{~m}$ (indicated by the longer lines starting from the ground in Fig. 4, here high backscatter intensity occurs together with very low $\sigma_{w}$ ). Starting around noon, the layer below 100 to $150 \mathrm{~m}$ becomes slightly better mixed and the vertical temperature gradient nearly vanishes in this layer but the stable stratification re-establishes after sunset. Especially during night-time we see several lifted inver- 

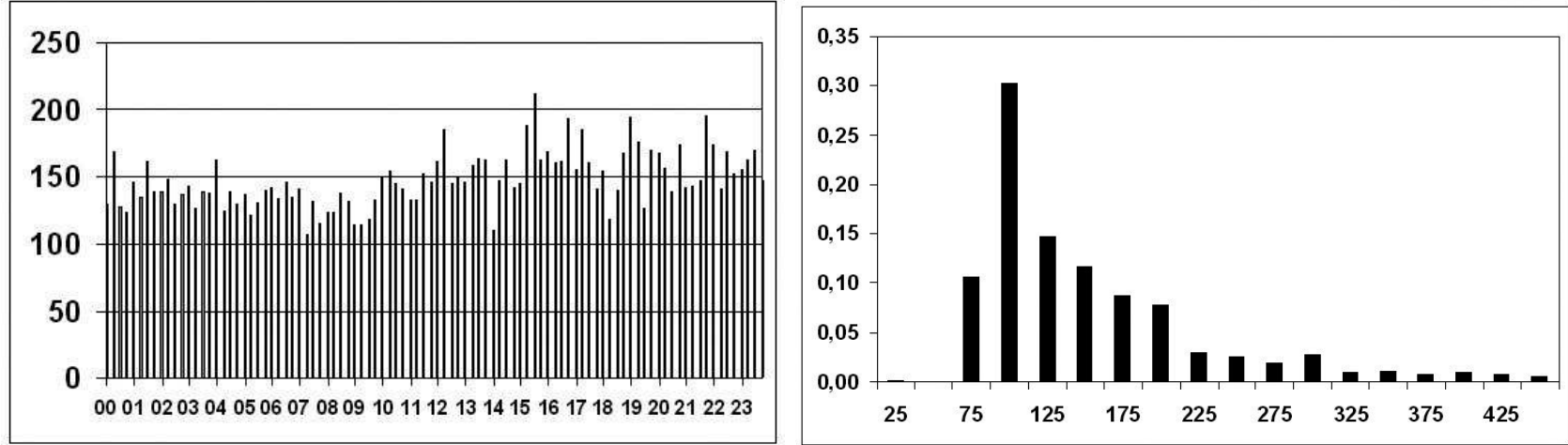

Figure 6: Mean diurnal variation of mixing layer height in $m$ plotted against the hours of the day (left) and frequency distribution of the mean daily-averaged mixing layer height in \% plotted against the height in $\mathrm{m}$ (right) in the Inn valley for January 1-18, 2006.
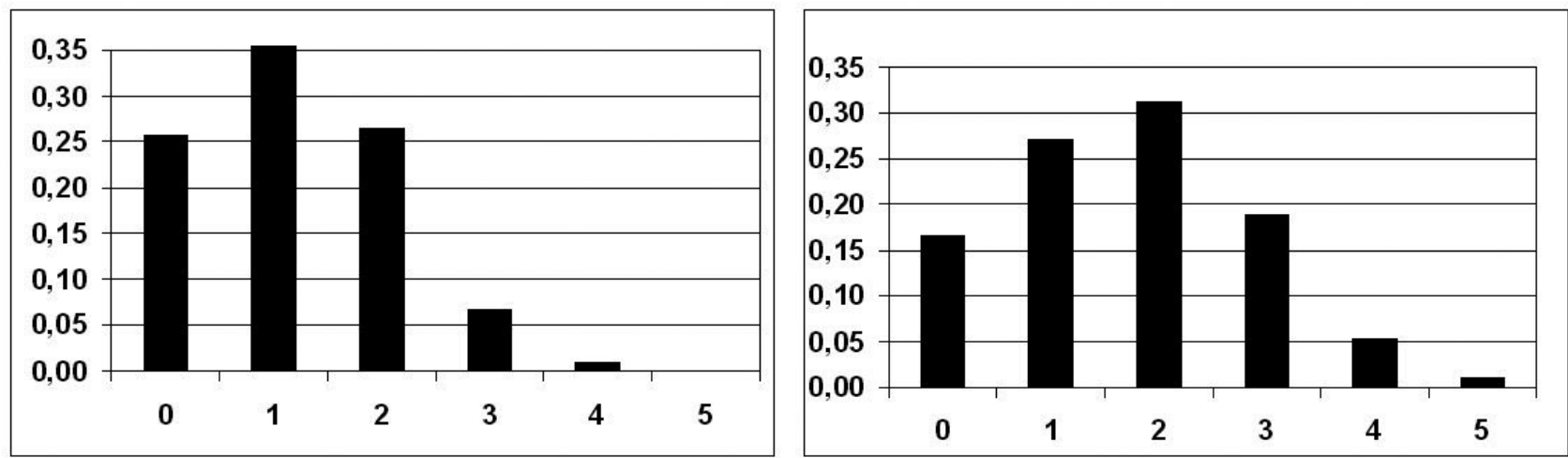

Figure 7: Frequency of the occurrence of multiple lifted inversions in $\%$ in the height interval between 140 and $1000 \mathrm{~m}$ from ceilometer data (left) and in the height interval between 60 and $1000 \mathrm{~m}$ for the sodar data (right). "0" means that no lifted inversion was detected.

sions which are detected equally by the sodar and by the ceilometer. In the late morning and around noon additional lifted inversions are mainly found by the sodar only. In the afternoon the layer underneath the second height $\mathrm{H} 4$ from below found from the ceilometer data is a layer with up-valley winds which appear more or less regularly between noon and about 7 p.m. Otherwise always down-valley winds are found. The evening of January 7 shows an example where the sodar clearly sees the formation of a new near-surface inversion in heights between 100 and $200 \mathrm{~m}$ which is not supported by the analysis of the ceilometer data. Inspection of the respective frame in Fig. 3 shows that at that time there was some fog at the surface.

Fig. 5 shows a special case with extremely pronounced vertical layering in the Inn valley. This happened on January 29, 2006. The acoustic backscatter intensity (left frame of Fig. 5) shows several secondary maxima below $700 \mathrm{~m}$ during the first half of the day. This structure is interrupted around noon when the down-valley wind system is stopped and is replaced by up-valley winds in the lower layers (below about $200 \mathrm{~m}$ until 14:00 CET and then below $400 \mathrm{~m}$ ). The quite high backscatter intensities in the lower $200 \mathrm{~m}$ between 15:00 and 18:30 CET show that also this flow is stably strat- ified. After 19:00 CET the down-valley wind starts to blow again and the vertical structure from the morning hours is re-established. The right-hand frame of Fig. 5 demonstrates that this layering is also visible from the wind direction recordings made with the sodar. We see that layers dominated by slope winds and layers dominated by down-valley winds appear alternatingly one above the other. The up-valley winds in the afternoon destroy this structure only temporarily. The main reason for the formation of a larger number of relatively thin stable layers one above the other in a larger valley is the interaction of nocturnal down-valley flow and nocturnal down-slope flows. Both flows are nearly laminar due to their small flow speed and high thermally stable stratification. Therefore the interaction between the different layers is very small and the layers can persist for hours without dissipating each other by friction. Unfortunately the ceilometer was not available after January 18, 2006.

Fig. 6 shows statistical evaluations of the mixing layer height in the Inn valley for the period January 118,2006 using the combined MLH results from both instruments (see (2.9)). We see (left-hand frame) that in winter this height has only a very small diurnal variation with slightly higher values in the second half of the day. This behaviour is explainable from what is seen in Fig. 
4. There it was shown that the surface-based stable layer is broken up only for a few hours in the afternoon. But the lowest lifted inversion which has been detected by the sodar (H2_1) usually persists also during this breakup period. The daily mean mixing layer height varies between $75 \mathrm{~m}$ and about $425 \mathrm{~m}$ with a peak frequency (right-hand frame of Fig, 6) of about $30 \%$ at $100 \mathrm{~m}$ above the valley floor. The four days displayed in Figs. 3 and 4 are examples for such a very low daily mean mixing layer height around $100 \mathrm{~m}$.

The occurrence of multiple lifted inversions is a special feature observed in Alpine valleys. Such a large number of lifted inversions within a few hundred of meters above ground level have rarely been observed by SODAR in level terrain. The authors are not aware of any study describing such a phenomenon. Fig. 7 shows the occurrence frequencies of multiple layering in the Inn valley in the period January 1-18, 2006 as seen by the two instruments. Isolated data points from the ceilometer indicating inversion heights of more than $1000 \mathrm{~m}$ have been ignored in these statistics. When comparing the two statistics one has to keep in mind that the LD40 ceilometer does not give MLH information below $140 \mathrm{~m}$. On the other hand the sodar very often detects an inversion below $140 \mathrm{~m}$. So it makes sense to compare the columns 0 to 4 in the left-hand frame of Fig. 7 with the columns 1 to 5 in the right-hand frame of this Figure. Doing so the results from the ceilometer and from the sodar data are quite similar. The result shows that two lifted inversions above the usually stable surface layer were very common in January 2006 (30 to $35 \%$ of all 15 min data intervals).

\section{Conclusions}

Remote sensing by acoustic and optical waves has proven to be a powerful tool to analyse the vertical structure of a valley atmosphere with high temporal resolution over a longer period. This study has been focused on the derivation of the mixing layer height (MLH) from remote sensing data. The analysis tools for the derivation of MLH from these soundings have been adapted to the needs for a hibernal valley atmosphere.

The hibernal valley atmosphere in the Inn valley shows several distinct features. One finding is that due to the snow cover in the investigation period in January up-valley winds have been rare and constricted to a few hours in the afternoon. Furthermore, we find that the atmosphere is dominated by a multiple layering caused by the interaction of the down-valley flow and the likewise stably stratified slope winds. A statistical evaluation for 18 days in January 2006 shows that two or even more lifted inversions above the usually stable surface layer are quite common. Only in $16 \%$ of all $15 \mathrm{~min}$ intervals we find no such inversion above the surface layer.
Both, sodar and ceilometer are able to depict different aspects of these special features. The sodar shows the wind conditions and - from a combination of backscatter and $\sigma_{w}$ data - the thermal structure. The ceilometer sees the vertical aerosol concentration profiles which arise from this wind and temperature structure. The information from both instruments is partly complementing each other. The combination of the results from the analysis of the acoustic and the optical backscatter intensities gives quite a complete picture of the vertical layering in an Alpine valley. The high temporal resolution of this data is a great advantage compared to radiosonde data twice or four times a day. This high temporal resolution permits a statistical evaluation of the occurrence of multiple vertical layering in a valley.

Possibilities for further studies could easily be imagined. It could, e.g., be interesting to investigate if there is a temporal delay between the acoustic and the optical information. This would give an indication how fast the aerosol distribution reacts to changing thermal structures of the atmospheric boundary layer (see also EMEIS and SCHÄFER (2006)). This would not only help to understand boundary layer dispersion processes but would also give further hints for the interpretation of optical backscatter intensities with respect to boundary layer structures. The multiple layering of the valley atmosphere which has been found in this study has large implications on the dispersion of air pollutants and traffic noise in the valley. This has still to be investigated in forthcoming studies..

\section{Acknowledgements}

This research has been funded by the European Union through the ALPNAP (INTERREG III B Alpine Space, reference number $\mathrm{D} / \mathrm{III} / 2.1 / 7)$ project. We like to thank Herbert HofFMANN and Andreas KRISMER (IMK-IFU) as well as Johannes VERGEINER, Esther GRIESSER and Friedrich OBLEITNER (University of Innsbruck, Department of Meteorology and Geophysics (IMGI), Innrain 52, A-6020 Innsbruck, Austria) for their contributions to this work. We also appreciate the permission of the Austrian army to install the sodar on their grounds. The suggestions of two anonymous reviewers have thankfully been incorporated into this study.

\section{References}

BEYRICH, F., 1997: Mixing height estimation from sodar data - a critical discussion. - Atmos. Environ. 31, 39413953.

EMEIS, S., K. SCHÄFER, 2006: Remote sensing methods to investigate boundary-layer structures relevant to air pollution in cities. - Bound-Layer Meteor. 121, 377-385.

EMEIS, S., M. TÜRK, 2004: Frequency distributions of the mixing height over an urban area from SODAR data. - Meteorol. Z. 13, 361-367. 
Emeis, S., Chr. Münkel, S. Vogt, W.J. Müller, K. SCHÄFER, 2004: Atmospheric boundary-layer structure from simultaneous SODAR, RASS, and ceilometer measurements.- Atmos. Environ. 38, 273-286.

Emeis, S., M. HARris, R.M. BANTA, 2007: Boundarylayer anemometry by optical remote sensing for wind energy applications. Meteorol. Z. 16, 337-347.

Engelbart, D., M. Kallistratova, R. Kouznetsov, 2007: Determination of Turbulent Fluxes in the ABL by Ground-Based Remote Sensing Techniques (a Review). Meteorol. Z. 16, this issue.

Münkel, C., S. EMeis, W.J. Müller, K. SChÄFer, 2004: Aerosol concentration measurements with a lidar ceilometer: results of a one year measuring campaign. - In: Klaus SCHÄFER, Adolfo CoMERON, Michel CARLEer, Richard H. PICARD (Eds.): Remote Sensing of Clouds and the Atmosphere VIII, Proc. SPIE, Bellingham, WA, USA, Vol. 5235, 486-496.

NeFF, W.D., R.L. Coulter, 1986: Acoustic remote sensing. Probing the Atmospheric Boundary Layer. - In: D.H. LEnsCHOW (Ed.), Amer. Meteor. Soc. Boston, MA, 201239.

REITEBUCH, O., S. EMEIS, 1998: SODAR-measurements for atmospheric research and environmental monitoring. Meteorol. Z. N. F. 7, 11-14.
Schäfer, K., S.M. Emeis, A. Rauch, C. Münkel, S. VOGT, 2004: Determination of mixing-layer heights from ceilometer data. - In: Remote Sensing of Clouds and the Atmosphere IX, Klaus SCHÄFER, Adolfo COMERON, Michel CARleER, Richard H. PICARD, Nicolas SifAKIS (Eds.): Proc. SPIE, Bellingham, WA, USA, Vol. 5571, 248-259.

SCHÄFER, K., S. EMEIS, W. JUNKERMANN, C. MÜNKEL, 2005: Evaluation of mixing layer height monitoring by ceilometer with SODAR and microlight aircraft measurements. - In: Remote Sensing of Clouds and the Atmosphere X, Klaus SCHÄFER, Adolfo T. COMERON, James R. Slusser, Richard H. PiCARD, Michel R. CARleER, Nicolaos SIFAKIS (Eds.), Proc. SPIE, Bellingham, WA, USA, Vol. 5979, 59791I-1-59791I-11.

Seibert, P., F. Beyrich, S.-E. Gryning, S. Joffre, A. RASMUSSEN, P. TERCIER, 2000: Review and intercomparison of operational methods for the determination of the mixing height. - Atmos. Environ. 34, 1001-1027.

SifAKIS, N., N. SOUlakellis, D. PARONIS, 1998: Quantitative mapping of air pollution density using Earth observations: a new processing method and application to an urban area. - Intern. J. Rem. Sens. 19, 3289-3300.

VERGEINER, I., E. DreiseitL, 1987: Valley Winds and Slope Winds - Observations and Elementary Thoughts. Meteor. Atmos. Phys. 36, 264-286. 